Research, part of a Special Feature on Balancing Ecology and Community using Cumulative Effects Models

\title{
The Challenge of Developing Social Indicators for Cumulative Effects Assessment and Land Use Planning
}

\author{
$\underline{\text { Ross E. Mitchell }}^{1}$ and $\underline{\text { John R. Parkins }}^{2}$
}

\begin{abstract}
This paper provides a synopsis on social indicators as relevant to cumulative effects assessment and land use planning. Although much has been done to better understand the social dimensions of environmental assessment, empirical work has been lacking on social indicators that could be used either as measurable inputs or outputs for cumulative effects assessment and land use planning in different kinds of communities and regions. Cumulative effects models currently in practice often fail to address deeper issues of community and regional well-being. Against this gap, social scientists are being asked to make reliable generalizations about functional, measurable relationships between certain social indicators and land use change or scenarios. To address this challenge, the Alberta Research Council held a two-day workshop in 2005 with social scientists. The workshop resulted in a list of prioritized social indicators that could be included in cumulative effects modeling/assessments and land use planning. The top five social indicators included population growth rate, education attainment, self-assessed quality of life, equity, i.e., distribution of benefits, and locus of control. Although consensus on social indicators and social thresholds for cumulative effects models was not reached, the insight gained from the workshop will help inform future cumulative effects assessment and land use planning.
\end{abstract}

Key Words: acceptable change; cumulative assessment; land use planning; social development; social impact; social indicators; social thresholds

\section{CUMULATIVE EFFECTS MODELS AND ASSESSMENTS}

Land managers and resource use professionals and technicians often utilize computer-based simulations to explore land use change and its cumulative effects on ecosystems and the human environment. These information tools for planners are known as cumulative effects models, integrated landscape management models, and strategic land use models, among other designations. Such models are used to assess potential future trends or scenarios of land use change based on plausible policy, management, and strategic options for a given region and set of conditions. Modelers are concerned about general patterns or trends in the face of uncertainty, rather than precise predictions of future outcomes (e.g., Sandker et al. 2010). Many resource-based industries and government agencies use these models, particularly in sectors that encompass large landscapes and long time horizons such as forestry, energy, and watershed planning. These models are generated with Geographic Information System (GIS) data based on historical patterns of landscape change, inventories, and surveys, as well as other information sources (e.g., Carlson et al. 2010).

\section{How to address linkages to the social environment}

Such models tend to be quite sophisticated and capable of determining ecological impacts for a given landscape over time. One common shortcoming, however, is how to meaningfully address key linkages between the biophysical and the social environment. Cumulative effects models currently in practice in North America generally do not address the social component; when they do, they tend to rely upon basic, primarily economic 
indicators such as revenues or jobs, and often fail to address deeper issues of community and regional well-being.

To make their scenarios more meaningful and complete, cumulative effects specialists are asking social scientists for generalizations about predictable, measurable relationships between certain socioeconomic indicators and land use change. Nonetheless, the programs of research on social trends and thresholds that are undertaken by social scientists often do not fit well with current computer-based ecological modeling activities. To date, research on social indicators for cumulative effects modeling has often been of a qualitative or descriptive nature, or concentrated on a limited number of indicators, with few causal or stochastic linkages to land use change. Moreover, causal relationships that unequivocally demonstrate social thresholds to agents of land use change are virtually nonexistent or poorly developed (L. Christensen and N. Krogman, unpublished manuscript).

\section{Social indicators in environmental impact assessments}

Despite this situation, some precedent exists for the application of social indicators to economic and environmental change within the regulatory context of environmental impact assessment. Where cumulative effects assessments, generally as part of environmental and social impact assessments, are required for regulatory permitting of development such as oil and gas production, mining, forestry, and intensive agriculture, then potential impacts on human communities are described and predicted using social indicators, e.g., employment, income, population growth, marital status, minority status, well-being or quality of life, and education attainment, among others. The literature on social impact assessment offers a useful starting point to identify social indicators that are relevant to project and policy level developments (Vanclay 2002).

Social indicators are defined as time-series data that allow for comparison over time, showing long-term trends, periodic changes, and fluctuations in rates of change. Importantly, social indicators are understood as an integrated set of usable information that can be reported spatially and temporally (Force and Machlis 1997). Because they are extremely diverse and dynamic, several issues must be taken into account when deciding which set of indicators to use. In particular, distribution across populations, e.g., gender, age, ethnicity, and income, requires further attention in the assessment of indicators. Likewise, communities are heterogeneous entities. The resources available to the community, e.g., institutional, economic, political, cultural, and natural, including control and distribution of available resources, are examples of intercommunity diversity, and merit further consideration.

As pointed out by Therivel and Ross (2007:366), "cumulative effects can also be social, for instance [the] decline of indigenous languages or traditional skills, changes in social structures, and increased reliance on the tourism economy." Given these complexities of indicators, the prospect of research at the project and community level moving to an assessment of social impacts within a regional and cumulative context is clearly a challenge (Duinker and Greig 2006). Part of this challenge is the inadequate knowledge about how social conditions may change in the context of resource-based development with multiple projects carried out over diverse geographical or administrative regions and timescales.

\section{Generalization to landscape metrics needed}

If cumulative effects models are to make practical sense for resource-based or rural communities and regulatory agencies alike, then generalizations for appropriate social indicators to landscape metrics are needed. Landscape metrics are measures of a characteristic(s) of a landscape feature or pattern, such as a land cover type, and may include characteristics such as fragmentation, diversity, and shape. These landscape metrics can also include the type of dominant economic activity; if agriculture is emphasized on a particular landscape, this activity will be associated with very different socioeconomic outcomes or change as compared with a landscape that is dominated by mining or energy development. As discussed below, such generalizations are not easily made when the human environment is brought into the equation. Still, understanding these functional relationships can help social scientists track or envisage landscape metrics caused by resource-based development for a given region, and could assist community groups and others to plan for expected, or unexpected, changes.

Admittedly, this is a topic of some controversy. Cumulative effects models need to be made more meaningful for resource managers, planners, policy 
makers, and communities alike, and social components are often a missing link. Although significant work has been conducted on social indicators in natural resource-based areas, little information exists as to whether these indicators can be designed in a mechanistic or deterministic sense for cumulative effects models; or for that matter, what are the most appropriate social indicators for scenario development using land use metrics? Answers to these kinds of questions are not easily forthcoming.

\section{Research purpose and questions}

Our purpose in this paper is to provide a synopsis on social indicators as relevant to cumulative effects models, and to provide some answers to three interrelated questions:

- What social indicators are most relevant in identifying the cumulative effects of resource-based industries and processing facilities over large landscapes and long time periods?

- Can we prioritize or weigh these social indicators by their perceived level of importance, especially for sensitive areas likely to experience extensive resource-based development?

- Can we determine if thresholds or limits exist for some of these indicators, and, if so, can these be applied in cumulative effects models?

We first provide a brief review of relevant literature, followed by a synopsis of a workshop on social indicators for cumulative effects models. We then discuss the workshop and summarize the main findings in the conclusion.

\section{Social dimensions of ecosystem and landscape management}

Seminal work on social indicators in a regional context can be found in several large-scale ecosystem management projects in the United States during the 1990s. One of these projects was the Interior Columbia Basin Ecosystem Management Project, which aimed to develop a comprehensive assessment of biophysical and social indicators for monitoring and assessment of sustainable ecosystem management. Drawing on a technical assessment of the project, Force and Machlis (1997) identified 36 specific variables and indicators that ranged from socioeconomic resources, cultural resources, and social institutions. Within their list of indicators, socioeconomic variables included education attainment, earnings, religious involvement, health, leisure activities, justice, and a range of natural resource uses such as energy consumption at the household level and agricultural production.

Kusel (2001) offered another seminal approach to social indicators research in the context of ecosystem management. For Kusel, an appropriate social unit of analysis for this evaluation was at the community level, which required attention to datasets and variables at the municipal scale. The community level is an important unit of analysis where livelihoods, a sense of place, identity, and community mobilization are most often organized and managed. The municipal level is also commonly the scale of social organization for "community capacity," defined in broad terms as the "ability to respond to external and internal stresses; to create and take advantage of opportunities; and to meet the diverse needs of residents" (2001:374). In terms of the assessment of capacity, Kusel identified the following assessment categories: physical, financial, human, cultural, and social capital, i.e., resources or assets. Missing from this list are natural capital and political capital, which are often cited in other approaches. This so-called "capitals" approach has evolved in several fields of study and it serves as the basis for community capacity assessment within the Canadian context (Beckley et al. 2008), as well as the international development context (IFAD 2010).

These concepts and methods from the published literature have been applied to specific resource management situations in Canada. For instance, in the forest sector, a community capacity model was utilized to determine a suite of social indicators for assessment in the Alberta Foothills Model Forest (Parkins and Beckley 2001). These social indicators provide insights into the changing socioeconomic conditions within local human communities, such as poverty rates, population growth, and the latent capacities of these communities to respond to local challenges and opportunities. Given the wide range of possible indicators that can be included for assessment, the conceptual frameworks from Kusel (2001) and Force and Machlis (1997) offer a way 
of selecting indicators and organizing indicators to address key sociological considerations such as community capacity.

In summarizing much of the social indicators literature, the Alberta Research Council (now called Alberta Innovates - Technology Futures) conducted a feasibility study called Social Indicators in Cumulative Landscape Effects Modelling (R. E. Mitchell and C. Davis, unpublished manuscript). The authors identify 11 categorical indicator themes pertinent to resource-dependent areas: livelihood, human capital, security, health, demographics, housing, community economic diversity, community capacity, natural/recreational amenities, cultural preservation, and political factors. More specific indicators are defined within each of these categories. Each indicator is ranked by assigning points based on its usability, its sustainability, and the number of times the indicator was mentioned in the literature. The final report presents six issues related to the use of social indicators in cumulative effects modeling: differential characteristics of communities, lessons learned from case studies, sustainability, objective vs. subjective indicators, measurement of indicators, and thresholds. The report concludes that although such models tend to be quite sophisticated and capable of calculating ecological footprints for a given landscape over time, one major shortcoming is how to meaningfully demonstrate key linkages between the biophysical and the social environment, or what the authors term as "sociological footprints." This shortcoming has not yet been resolved; given the lack of coordinated research into such linkages, this conundrum will likely continue for some time.

\section{Linkages between land use change and social outcomes}

Beyond these conceptual approaches to social indicators research, however, recent research provides some insight into the linkages between land use change, employment, and social outcomes. For instance, one study by Stedman et al. (2004) shows that socioeconomic outcomes as measured by average income and education attainment are significantly related to changes in employment levels within a particular resource-based sector. As an example, within Canada, a rural region that is predominantly based on agriculture is likely to provide a higher number of jobs than other regions, but these jobs are also likely to be lower paying. In another example, employment in the forest industry is often linked to higher incomes in western Canada, but forest workers tend to have lower education attainment levels than their urban counterparts. This study, along with others (e.g., Patriquin et al. 2007), makes use of customized census data and multivariate regression techniques to determine a statistical coefficient between levels of employment dependence on a particular sector of the economy and a suite of social outcomes. Utilizing census data in this way can help to identify more quantitative linkages between changes in land use, employment, and social indicators such as education, income, and mobility.

Another case study of relevance here is the regional cumulative effects assessment completed in 2007 for the Great Sand Hills of southwest Saskatchewan (Noble 2008). The approach taken was to systematically evaluate the cumulative effects of multisector land use and surface disturbances under different future scenarios, including a desired conservation-based scenario. The assessment framework had three main phases: a baseline to characterize the current and cumulative biophysical, economic, and social conditions of the region; the identification of historic trends in land use and associated cumulative change, conceptualized as "surface disturbance"; and the development, projection, and assessment of alternative land use scenarios, along with a recommended preferred scenario and guidelines for implementation, mitigation, and monitoring. The consequences associated with alternative futures were explored, "identifying a preferred future based on ecological, social, and economic objectives, and devising the means to achieve it" (Noble 2008:86). The social indicators used included regional economic change, the economic contribution to government, selfassessed quality of life, First Nations land use, and governance, among others. The indicators were then assessed at the broader regional scale and either modeled and linked directly to land use models, or assessed for potential effects against modeled outcomes. Then, the social implications of cumulative change under each scenario were assessed. Over 60 recommendations were identified, along with specific targets, thresholds, and objectives for select ecological components.

The Great Sand Hills study produced an integrative and highly structured spatial analytical model of preferred conservation-based scenarios for future land use and development. The scope and scale of 
these types of assessments can be time and resource intensive, and are often done with an incomplete knowledge of key correlations. Their value, however, is a shared, improved understanding of possible cumulative change in the region. Although challenges remain in identifying highly deterministic linkages between cumulative land use change and social outcomes, these studies offer a step toward determining social outcomes from various land use scenarios that can be developed by cumulative effects assessment models.

\section{EXPERT WORKSHOP ON SOCIAL INDICATORS}

In May 2005, the Alberta Research Council held a two-day workshop with leading researchers in the fields of social indicators and landscape modeling. This was a face-to-face opportunity for social scientists to meet with cumulative effects modelers and determine the most appropriate social indicators for tracking changing landscapes and land use practices. Among the 13 workshop participants were five academics, three graduate students, three research scientists with government agencies, and two consultants. All attendees had prior experience with social indicators through their work in resource management, research, and/or cumulative effects modeling. A key outcome was to identify and evaluate common social indicators that held the best promise for use within cumulative effects models. Although several years have passed since the workshop, most of the issues discussed around social indicators and cumulative effects modeling and assessment remain ongoing challenges.

\section{Workshop methods and process}

In the workshop, we first presented a prior background study on social indicators for cumulative effects modeling (R. E. Mitchell and C. Davis, unpublished manuscript). We then gave an overview of how land use in Alberta has been growing at an unprecedented rate, with multiple and overlapping effects, and how these models simulate future landscapes. We then asked participants whether or not it was possible to determine a suite of useful social indicators that could be included in cumulative effects models. One model developed by Forem Technologies, ALCES, an Alberta-based Integrated Landscape Management Model, was discussed at length because of its familiarity by many participants.
Prior to our workshop, we circulated a list of questions for an initial round-table discussion. Because of limitations of space, results from two of the five questions discussed in the workshop are presented below; for its direct relevance to the paper, most of the discussion in this section is focused on Question 2.

Question 1: Can thresholds for certain key social indicators be determined? All participants agreed that thresholds are a controversial subject for social scientists. A magical number at which a given community will be unalterably transformed does not generally exist within the published literature (L. Christensen and N. Krogman, unpublished manuscript). Instead, some suggested that a preferred approach would be to ask communities directly how much risk they are willing to take on as a trade-off for the benefits that development will presumably generate. This relates to the resiliency of people and communities, or the level of acceptable change. An analysis of trends could also be used in the place of benchmarking or establishing thresholds. For instance, Anielski's (2001) Genuine Progress Indicator (GPI) provides a number of examples of analyzing trends as opposed to measuring thresholds. These challenges aside, it also bears mentioning that some thresholds can be set for certain social indicators. For example, thresholds can be set based on local capacity for health care, e.g., population, physician ratios. Under different scenarios, varying levels of stress can be detected and assessed based on changes to the current capacity to deliver health care.

Question 2: What do you think are the most important social indicators of well-being for areas near resource-based developments? At this stage of the workshop, we invited participants to work collectively to develop a list of social indicators. Both new and previously discussed indicators were written on flip chart paper and displayed on the walls. Each participant in the workshop was then given 10 blue and 10 yellow dots. Blue dots indicated which indicators were most meaningful for cumulative effects modeling and thought to be quantifiable and easily measured, even though data may not currently exist. Yellow dots were for the indicators thought to be also meaningful for cumulative effects modeling, but not necessarily quantifiable and less easily measured. Some participants placed both blue and yellow dots on certain indicators, signifying their uncertainty on whether the indicator was quantifiable or not. The top 30 results are listed below in Table 1. An 
Table 1. Prioritized list of social indicators.

\begin{tabular}{|c|c|c|}
\hline Social Indicator $\dagger$ & blue dots $\$$ & yellow dots§ \\
\hline population growth rate & 11 & 0 \\
\hline self-assessed quality of life & 10 & 6 \\
\hline equity - distribution of benefits & 10 & 9 \\
\hline education rate & 8 & 0 \\
\hline locus of control & 7 & 1 \\
\hline health & 6 & 3 \\
\hline net savings & 6 & 0 \\
\hline local control of businesses & 6 & 0 \\
\hline sense of control & 5 & 2 \\
\hline sense of place & 4 & 7 \\
\hline net regional benefits & 4 & 5 \\
\hline sense of cultural vitality & 4 & 2 \\
\hline economic diversity & 3 & 0 \\
\hline social networks & 3 & 2 \\
\hline resilience & 3 & 8 \\
\hline freedom from fear (level of security) & 3 & 0 \\
\hline infrastructure and service development & 3 & 0 \\
\hline democratic decision making & 2 & 1 \\
\hline water & 2 & 0 \\
\hline volunteerism & 2 & 1 \\
\hline diversity of net regional benefits & 2 & 0 \\
\hline entrepreneurship & 2 & 1 \\
\hline amount/availability of social services/facilities & 2 & 0 \\
\hline suicide rate & 2 & 0 \\
\hline alcoholism, smoking, life expectancy & 2 & 0 \\
\hline confidence in formal institutions & 2 & 7 \\
\hline biodiversity & 1 & 3 \\
\hline access to sustainable livelihoods & 1 & 1 \\
\hline individual identity & 1 & 3 \\
\hline social institutions for protecting land resources & 1 & 1 \\
\hline
\end{tabular}

$\dagger$ As noted, certain economic and social indicators overlap;

\$ More easily measured;

$\S$ Less easily measured. 
additional eight indicators that were suggested are not included because none were ranked as easily measured; still, one of these, leadership, was given five yellow dots, indicating its relative importance. At least three comments can be made to summarize the overall exercise of placing sticky dots next to priority indicators.

\section{Workshop results}

First, selected indicators generally fell into one of two groups: quantitative indicators, i.e., interval or ratio variables, or qualitative indicators, i.e., descriptive or categorical variables. This brings up two challenges: not everyone may have the same understanding about measurability, and many indicators can be expressed in either format; for example, population growth rate may be characterized by descriptors such as "high" or "low," but is generally expressed as a percentage of the overall population.

Second, some expected indicators were not evaluated during this exercise; for example, although "sense of cultural vitality" was mentioned, many other possible indicators related to culture were ignored such as loss of language, traditional knowledge, ethnic diversity, and religious or spiritual belief. This may have been reflected by the similar cultural background of the participants.

Third, some of the chosen indicators such as water and biodiversity were environmentally related, instead of social or economic. Although some participants felt that these indicators are important to many individuals and communities, and are often considered as valued components, these environmental indicators should likely have been left off the table and replaced by more directly relevant socioeconomic or cultural indicators.

Of the five top ranked indicators, three are discussed here: equity (distribution of benefits), quality of life (self-assessed), and locus of control (psychological). Population growth rate is relatively straightforward and already in use in most cumulative effects models. It also has some known causal links to, for example, deforestation and pollution in places or development scenarios where in-migration is common, e.g., newcomers in search of employment and business opportunities. Another conventional indicator ranked high among workshop participants was the rate of education attainment. In the literature, education rate refers to several types of rates: for example, the postsecondary education rate and the adult literacy rate are often cited, and expressed in terms of percentage of population. Education attainment is often used because of the link to human capital as a major component of community capacity. The other three are less well known in the context of cumulative effects and require further elaboration.

\section{Equity}

The equity model argues that a number of demographic and psychological variables affect people's perceptions of fairness and interactions with others. Equity was left undefined by the workshop participants. Several types of equity exist, for example, distributional equity, i.e., avoiding unfair or high environmental costs on vulnerable populations, gender equity, and intra-generational equity, i.e., in the context of sustainability, providing future generations with the same environmental potential as presently exists.

Equity could be measured by several methods. For example, composite indicators are multidimensional measures produced by combining various kinds of social indicators. One popular and widely used composite indicator is the Human Development Index (HDI), which was developed by the United Nations Development Program (UNDP) in 1990. The HDI combines income, life expectancy, adult literacy, and school enrolment. An even more comprehensive equity index may measure regional, gender-related, racial, ethnic, and religious disparity in terms of human development.

The challenge with composite indicators is that the more complex they are, the harder to unravel the link of the social effect represented by the indicator to a certain land use change. Easily understandable relations are important if the end goal is to integrate social knowledge with that of biophysical researchers, but designing inclusive tell-all social indicators might blur important relationships between land use change and society. Seeing the trees in the forest is essential to understanding the whole.

\section{Quality of life}

Various social indicators could be linked with environmental or economic indicators to measure quality of life for a given model. Although it is not 
a given that resource-based development will change quality of life, either individually or in a community, evidence is growing that some positive effects are more likely overall.

Researchers in the field of economics have linked quality of life with subjective measures such as selfreported happiness and life satisfaction. Key insights from this literature suggest that, until close to age 50, happiness has more to do with satisfaction with family life and quality of work and less to do with financial gains and personal health (Easterlin 2006). With several decades of evidence in this field of study, research shows that happiness levels appear to remain constant even in light of substantial increases in income, a phenomenon known as the "Easterlin Paradox" (Easterlin 1974, Clark et al. 2008).

Quality of life is also affected by one's surroundings or sense of place. For instance, urban expansion may generate social stress in rural areas due to an influx of vacationers, second homeowners, and additional permanent residents such as retirees. This urban invasion into rural settings in places such as southern Alberta can result in a loss of rural community character and overall quality of life, creating lifestyle conflicts between newcomers and long-term residents such as ranchers (Duke et al. 2003). In another context, in Newfoundland, people engage in subsistence harvesting to supplement incomes, and, in rural areas, people often build their own mortgage-free homes with the help of family and neighbors. This participation in traditional activities and sharing increases one's social status, and contributes to a sense of place and freedom from debt, with a correspondingly positive impact on perceptions of quality of life (den Otter and Beckley 2002). Others feel that larger and medium-sized centers, or more developed communities, provide residents with greater access to amenities such as educational and social opportunities, and lead to a higher quality of life (Walisser et al. 2006).

\section{Locus of control}

Locus of control is a term that refers to the extent to which individuals believe that they can control events that affect them. The concept can be traced to Karl Marx's theory of alienation; in an emerging system of industrial production under capitalism, workers inevitably lose control over their lives and destinies by being deprived of control over the means of production. Locus of control, however, is more generally attributed to psychologist Julian Rotter's work on social learning theory of personality (Rotter 1954). Locus of control is manifested by the belief that individuals can control events that affect them, and can either be "internal," i.e., the person believes that they control their life by their own behavior and actions, or "external," i.e., the person believes that their environment, some higher power, fate, chance, or even other people, control their decisions and their life.

The locus of control has also been discussed in the resource-based literature. For example, an agricultural production study illustrates how the locus of control shifted in the latter half of the 20th century from family farms to off-farm or industrial firms, and from producers to buyers (Welsh 1997). In this sense, locus of control over agricultural production decisions is largely external, with a desire expressed by some to strengthen the internal locus of control. In other contexts, the governance of resources is sometimes negotiated by government with resource-based communities for a shared locus of responsibility; this comanagement system has been advocated by some to improve the management regime for local resources, to generate conditions for sustainability, to improve prospects for economic development, and to provide greater autonomy for local communities in decision making about natural resources (Reed 1993). In short, locus of control is being able to maintain some sense of autonomy. Major changes, particularly economic, can be hard on people and communities, who may lose the sense that "my fate is in my own hands", and instead, start feeling helpless in the face of these changes.

In our workshop, four possible measures of locus of control were listed: extent of comanagement, accuracy of promises from government and industry, percent of local ownership of infrastructure, and land tenure. Locus of control can also be measured by surveys using Likert scales in which the respondent is asked to evaluate a statement according to some kind of subjective or objective criteria, and generally the level of agreement or disagreement is measured, allowing for reporting of percentages. Research is lacking, however, on how locus of control may inform, or in turn be affected by, cumulative land use change. In addition, locus of control measures may likely be best addressed in follow-up and monitoring activities, as well as in the negotiation of specific agreements with communities that commit 
proponents and government to issues such as hiring preferences, training and education support, and improvements to infrastructure and social services.

\section{DISCUSSION}

Our workshop results bring out the challenges of selecting appropriate social indicators for cumulative effects assessment and land use planning. We recognize that the social indicators identified and prioritized in the workshop are not necessarily the best ones in every situation, and definitely not the only ones to use for cumulative effects modeling. Communities and other stakeholders will have a superior understanding of what they value and what needs to be assessed and monitored at the local level. For instance, a valid quality of life assessment must be related to the values and the diversity of interests of a community and its citizens. Values will differ among communities and other stakeholders. Given this situation, there is only so much that an expert workshop on social indicators can achieve.

Although consensus on social thresholds was certainly not reached in our workshop, the topic generated considerable discussion, illustrating the need for future research. More definitive work is needed to be able to estimate trends or even generalizations for specific study areas. Gloomy boom and bust scenarios attached to resource-based development are what researchers are hoping to avoid by using models to simulate impacts on the social and environmental setting. If the model scenarios are run and presented to communities as potential outcomes of development, it is hoped that stakeholders such as communities will be able to make better choices for themselves based on these scenarios. Communities will likely listen to scientists who say, "Based on our data, if development proceeds in your community the same way as it did in X community, then scenario A (or B, C, etc.) could occur." Thus, a combination of applied and basic research is likely the best approach for increasing robustness of results.

Current social indicators are likely insufficient in themselves to build reliable and plausible scenarios for complex communities and multiple resource use. Specific, model-friendly social indicators are needed that aim toward sustainable communities as defined by the published literature. The incorporation of a variety of social indicators and subsequent testing are critical steps on the path to their acceptance in cumulative effects assessments. Against these complexities, and for certain indicators, it may be that current cumulative effects models are inadequate for resource use planning in which acceptable limits of change are fuzzy and needed data is unavailable. Other nonsimulation approaches could be taken for such cases, including conventional sociological methodologies such as comparative case study techniques that draw on experiences from other jurisdictions to anticipate future impacts within a chosen study region.

Our workshop responses also appear to reinforce that we do understand many of the issues around resource-based development, and that many of the indicators listed in Table 1 are readily available from project-based environmental impact assessments. What is lacking is how to scale relevant indicators up to a given region and link them better to broader land use change, as concluded by Therivel and Ross (2007).

We now return to the three questions that have guided this research, and provide some answers. The first two questions have been combined into one because of their complementary nature.

\section{Selecting and prioritizing social indicators}

Which social indicators are most relevant in identifying the cumulative effects of resource-based industries and processing facilities over large landscapes and lengthy time spans? Can we prioritize or weigh these social indicators by their perceived level of importance, especially for sensitive areas likely to experience extensive resource-based development over several years?

The workshop outcomes provide several important insights into a shortlist of social indicators for cumulative effects assessment. Most definitions of cumulative effects assessment pay attention to multiple stressors or factors that impact valued aspects of the ecosystem. Our focus is on the human ecosystem and components of this system that are most critical for health and long-term well-being. Expert assessments of what matters in this regard are instructive here, and our paper contributes to ongoing debates among experts in terms of what is important and what is practical to address within an impact assessment context. 
Our list of indicators as reported in Table 1 can be used as a general guide for selecting social indicators for cumulative effects modeling. This list can be understood in other ways as well. Within the literature on social indicators, there is a distinction between indicators that are identified by experts, i.e., a top down approach, and indicators that are identified by community members, i.e., a bottom up approach. This distinction can also be described as outsider expertise vs. insider expertise. In the process of identifying and prioritizing indicators, it is possible to overcome these distinctions with a hybrid approach to indicators development, whereby researchers identify general categories of indicators that are important for cumulative effects assessment, such as quality of life or equity, and then invite community members to identify and prioritize the more specific indicators or variables of interest within these broader categories. For example, although equity issues are understood to be a key category or domain of interest, within this domain there can be more specific discussions with communities of a given region about what forms of equity are most relevant; for example, income equity at the household level, equity between generations, gender equity, and so on. In this way, local expertise is brought to bear on the exact form of equity assessment that is relevant for cumulative effects assessment within a given region.

Questions of selecting and prioritizing indicators are only partially addressed through expert-based exercises such as this workshop. To actually determine a final list of indicators and make decisions about what areas of social development are priorities for a given region, it is our view that more community involvement is required. Through community workshops, focus groups, interviews, or survey research, some form of community-based assessment is required in determining and prioritizing social indicators for cumulative effects assessment.

We also understand that social indicators for cumulative effects assessment are often closely associated with a fairly conventional list of social variables such as education, employment, and income. Although these indicators are commonly associated with quality of life and community wellbeing, defining social indicators can differ widely among people and sets of circumstances. In a very real sense, each and every indicator that is incorporated into comprehensive ecosystem-based models, such as ALCES mentioned earlier, are socially defined and prioritized; therefore, by default they are also social indicators. From this definition, a social indicator is any social, economic, or biophysical indicator that is socially defined, and is therefore valued and prioritized by humans within a given assessment context.

To understand social indicators in this way implies that we focus our energies more on the social processes that feed into a determination of these social indicators. Questions to ask include the following:

- How do we arrive at and prioritize a list of indicators for cumulative effects assessment?

- Who is at the table when these decisions are made?

- What interests are reflected by these indicators?

- Who is privileged in this process and who is left out?

These questions are germane to an understanding of the social processes that undergird all cumulative effects assessments, regardless of how explicitly they address indicators such as employment, income, or education attainment. It is our view, therefore, that we need to pay as much attention to the social processes as we do the social indicators of cumulative effects assessment.

\section{Determining thresholds or limits}

Can we determine if thresholds or limits exist for some of these indicators, and, if so, can these be applied in cumulative effects models? When it comes to determining thresholds for social indicators, we gain very little guidance from the workshop described above and even less from published literature. Simply stated, there are no hard and fast rules in this regard, mainly because there is no agreement among experts on what they might be. One can imagine that some basic level of economic activity might be required for the proper functioning of a community, as measured by number of businesses or jobs. There may also be some basic limits to the number of services such as schools, stores, or medical facilities that might be required for the proper functioning of communities. However, even these kinds of limits are subject to debate and local interpretation. 
Therefore, it is our view that a better approach to determining thresholds and limits for a proposed development is to focus on social trends within a historical context, i.e., examining changes in indicators such as rates of employment or poverty over long periods of time, ideally pre- and postdevelopment, and then explore the extent to which multiple, cumulative impacts have contributed positively or negatively to these trends. Another approach to trend analysis is through comparative analysis, in which social trends in one community are compared with social trends within another community, i.e., either selecting both communities affected by a given development, or selecting one that is affected and one that is not to serve as a control. Using this approach, specific cumulative impacts for a given set of communities may be identified, which could enhance an understanding of the limits of acceptable change.

Researchers such as Krogman and Christensen (unpublished manuscript) have taken other approaches to determining thresholds and limits by asking other kinds of questions. For instance, from a community perspective, what are the levels of acceptable change in this context, what are the historical antecedents to these contemporary changes, and what can we learn from previous social impacts and social changes that can be applied to questions of acceptable social change in this context? These approaches are more descriptive and oriented toward case studies and historical account, which tend to fit very poorly into the mechanistic domains of cumulative effect assessment models and scenario developments.

These differences in research methods, forms of data, evidence, and knowledge generation represent major challenges, particularly as cumulative effects assessment becomes increasingly oriented toward comprehensive quantitative models. It may be the case that to achieve more comprehensive assessments, we must learn to work more efficiently and generously with diverse research methods and epistemological approaches that include more historical, descriptive, and democratic accounts of thresholds and limits. In this way, cumulative effects assessment may never be entirely contained within a comprehensive computer-based modeling activity.

In terms of social process, as discussed in the previous section, a more promising approach to these questions of thresholds and limits may be to feedback results of computer-based models and scenarios to community members in ways that invite different kinds of questions. As an example, if our computer models are suggesting that social and biophysical conditions will change in specific ways because of resource-based development, what are the limits of acceptable change in this context? What is the level of acceptable change for communities and citizens within a region of interest? What kinds of social changes are we capable of absorbing without fundamentally altering what we value within these communities? How much additional crime or homelessness is the community able to support, how many more patients or students can the existing facilities accommodate, how much more traffic can be tolerated, and so on? In this way, a determination of thresholds and limits is socially defined by those who are most closely affected by these changes.

\section{CONCLUSION}

Our workshop ended with speculation on related questions that could be addressed in further studies to fill in some of the remaining gaps. Five take-home messages are discussed below.

1. Ask communities to discuss and determine their level of acceptable change with respect to land use or resource-based development. Communities need to be adequately informed in a timely, inclusive, and open manner, not only about the proposed development but also about its potential cumulative effects. In this way, communities will be able to influence an understanding of social thresholds and levels of acceptable change.

2. Study the relationship of employment changes relative to the amount of time spent on the land engaged in traditional activities such as hunting, trapping, fishing, and sharing. Development may not be as negative as originally thought on cultural activities. Aboriginal people may use their earnings from development activities to pursue traditional activities, and because of the rotational work, may have the time available to go on longer hunting and fishing trips. The question is if, over time, the cumulative effects of the wage economy will continue to erode traditional activities, or if satisfactory arrangements can be made that would 
accommodate the pursuit of traditional activities within the expressed need for more jobs and training.

3. Study communities that have survived boom and bust cycles, i.e., not only the communities where anticipated negative impacts did not occur, but also the ones where they did occur yet the community somehow overcame them. Several case studies suggest that communities that foster cohesion, encourage an entrepreneurial spirit, engage forward-looking political leadership, and create strong networks of volunteer organizations are much better positioned to beat the boom and bust cycle ( for example see Walisser et al. 2006). The legacy of resource development can also be a positive one if communities can negotiate mutually beneficial agreements with developers and regulators alike.

4. Ask the computer modelers whether their work has helped the community, i.e., has it opened up a dialogue with communities or helped decision makers reach their decisions more easily? On one hand, community-based indicators could make models more participatory and locally relevant, and may be more equitable or ethical; on the other hand, such indicators may be naive compared with some expert-led indicators, may present serious technical and logistical issues, or may be too qualitative for convenient use in land use models. Still, modelers stand to gain from more discursive actions with communities and decision makers alike as the act of informed discussions around these topics could help define and prioritize social indicators.

5. Conduct comparative and longitudinal case studies of select communities with different development experiences, historical and ongoing. The social indicators as discussed in this paper are extremely diverse and dynamic, and vary across communities, even those clustered within a relatively small region. There may be differences over time and between communities in the resources available to the community, e.g., institutional, economic, political, and natural; income distribution; and educational achievement. This, in turn, may be further complicated by differences in ages, gender, ethnicity, population growth rates, social cohesion, and so on.

Our workshop results offer a step forward in directing future research on social indicators. Workshop participants were able to identify a suite of social indicators that are measurable and germane to the social dimensions of cumulative effects assessment. Although considerable work remains in terms of developing integrated computer-based models of cumulative impact assessment that include robust social components, there are clear directions from the published literature and from subject matter experts on building, prioritizing, and testing social indicators for cumulative effects assessment. Our paper also sheds light on the process of determining which social indicators could be prioritized and adapted for a given region and set of industrial or other developments, e.g., recreation, agriculture, residential. The focus has to shift to more greatly involve affected communities in this process if social sustainability is a desired end.

Responses to this article can be read online at: http://www.ecologyandsociety.org/voll6/iss2/art29/ responses/

\section{Acknowledgments:}

We extend our appreciation to Environmental Resources Management (ERM) for their financial support of this paper. We thank the reviewers for their useful suggestions to improve this paper. The authors also thank the Alberta Research Council (now Alberta Innovates - Technology Futures) for their support of the workshop, along with all of the workshop participants. In particular, we wish to give special mention to one of the participants, $D r$. William (Bill) R. Freudenberg, Dehlsen Professor of Environmental Studies at the University of California, Santa Barbara, who passed away on December 28, 2010. We dedicate this article to Bill, who in addition to being an exemplary scholar and caring mentor, was also a good friend. 


\section{LITERATURE CITED}

Anielski, M. 2001. The Alberta genuine progress indicator (GPI) accounting project: charting a future for all Canadians. The Pembina Institute, Edmonton, Alberta, Canada.

Beckley, T. M., D. Martz, S. Nadeau, E. Wall, and B. Reimer. 2008. Multiple capacities, multiple outcomes: delving deeper into the meaning of community capacity. Journal of Rural and Community Development 3(3):56-75.

Carlson, M., T. Antoniuka, D. Farr, S. Francisa, K. Manuel, J. Nishi, B. Stelfox, M. Sutherland, C. Yarmoloy, C. Aumann, and D. Pan. 2010. Informing regional planning in Alberta's oilsands region with a land-use simulation model. International Congress on Environmental Modelling and Software. Fifth Biennial Meeting, Ottawa, Ontario, Canada.

Clark, A. E., P. Frijters, and M. A. Shields. 2008. Relative income, happiness, and utility: an explanation for the Easterlin Paradox and other puzzles. Journal of Economic Literature 46 (1):95-144.

den Otter, M., and T. Beckley. 2002. "This is paradise": monitoring community sustainability in the Western Newfoundland Model Forest using subjective and objective approaches. Information Report M-X-216E. Natural Resources Canada, Canadian Forest Service, Atlantic Forestry Centre, Fredericton, New Brunswick, Canada.

Duinker, P. N., and L. A. Greig. 2006. The impotence of cumulative effects assessment in Canada: ailments and ideas for redeployment. Environmental Management 37(2):153-161.

Duke, D., M. Quinn, B. Butts, T. Lee-Ndugga, and K. Wilkie. 2003. Spatial analysis of rural residential expansion in Southwestern Alberta. Miistakis Institute for the Rockies, Faculty of Environmental Design, University of Calgary, Calgary, Alberta, Canada.

Easterlin, R. 1974. Does economic growth improve the human lot? Some empirical evidence. Pages 89-125 in P. A. David and M. W. Reder, editors. Nations and households in economic growth. Academic Press, New York, New York, USA.
Easterlin, R. A. 2006. Life cycle happiness and its sources: intersections of psychology, economics, and demography. Journal of Economic Psychology 27(4):463-482.

Force, J. E., and G. E. Machlis. 1997. The human ecosystem part II: social indicators in ecosystem management. Society and Natural Resources 10:369-383.

International Fund for Agricultural Development (IFAD). 2010. An IFAD sustainable livelihoods framework. IFAD, Rome, Italy. [online] URL: http ://www.ifad.org/sla/framework/index.htm.

Kusel, J. 2001. Assessing well-being in forest dependent communities. Journal of Sustainable Forestry 13(1/2):359-384.

Noble, B. 2008. Strategic approaches to regional cumulative effects assessment: a case study of the Great Sand Hills, Canada. Impact Assessment and Project Appraisal 26(2):78-90.

Parkins, J., and T. Beckley. 2001. Monitoring community sustainability in the Foothills Model Forest: a social indicators approach. Information Report M-X-211E. Natural Resources Canada, Canadian Forest Service, Atlantic Forestry Centre, Fredericton, New Brunswick, Canada.

Patriquin, M., J. R. Parkins, and R. C. Stedman. 2007. Socioeconomic status of boreal communities in Canada. Forestry: An International Journal of Forest Research 80(3):279-291.

Reed, M. G. 1993. Governance of resources in the hinterland: the struggle for local autonomy and control. Geoforum 24(3):243-262.

Rotter, J. B. 1954. Social learning and clinical psychology. Prentice-Hall, New York, New York, USA.

Sandker, M., B. M. Campbell, M. Ruiz-Pérez, J. A. Sayer, R. Cowling, H. Kassa, and A. T. Knight. 2010. The role of participatory modeling in landscape approaches to reconcile conservation and development. Ecology and Society 15(2): 13. [online] URL: http://www.ecologyandsociety.org/vol15/ iss2/art13/.

Stedman, R. C., J. R. Parkins, and T. M. Beckley. 2004. Resource dependence and community well- 
being in rural Canada. Rural Sociology 69 (2):213-234.

Therivel, R., and B. Ross. 2007. Cumulative effects assessment: does scale matter? Environmental Impact Assessment Review 27(5):365-385.

Vanclay, F. 2002. Conceptualising social impacts. Environmental Impact Assessment Review 22 (3):183-211.

Walisser, B., B. Mueller, and C. McLean. 2006. The resilient city. The World Urban Forum 2006 Vancouver Working Group Discussion Paper. Ministry of Community Aboriginal and Women's Services, Government of British Columbia, Vancouver, British Columbia, Canada. [online] URL: http://sustainablecities.net/docman-resources/ cat view/110-resources/192-world-urban-forum/193wuf-iii-2006.

Welsh, R. 1997. Vertical coordination, producer response, and the locus of control over agricultural production decisions. Rural Sociology 62 (4):491-508. 